\title{
Doğuştan çarpık ayakta yumuşak doku cerrahisi
}

\author{
Surgical soft tissue treatment in congenital clubfoot
}

\author{
Ali Turgut, Önder Kalenderer
}

Tepecik Eğitim ve Araştırma Hastanesi, İzmir

\begin{abstract}
Doğuştan çarpık ayak, muhtemelen en sık karşılaşılan konjenital ortopedik bozukluktur. Bu bozukluğun patoanatomisinde, talus çevresindeki kalkaneus, naviküler ve küboid kemiklerin mediyal ve plantara dönmeleri ve mediyal taraf, arka taraf yumuşak dokularında oluşan kısalma ve gerginlik önemli rol oynamaktadır. Bu hastalığın tedavisinde ilk basamak, olabilecek en erken dönemde konservatif tedaviye başlamak olmalıdır. Bazı durumlarda cerrahi tedavi gerekli olabilir. Yumuşak dokulara yönelik yapılacak cerrahi tedavi, bu hastalarda düzelme sağlayabilecek ve ikincil kemik deformitelerinin gelişmesini engelleyebilecektir.
\end{abstract}

Anahtar sözcükler: total subtalar gevşetme; çarpık ayak; PEV; çocuk
Congenital clubfoot is probably the most common congenital orthopedic disorder. In this disorder's pathoanatomy; turning of the calcaneus, navicula and cuboid bones around the talus towards medial and plantar direction, and also shortening and tension of posterior and medial soft tissues play an important role. Beginning the conservative treatment as early as possible should always be the first step. However, surgery may be required in some cases. For these patients, surgical treatment for soft tissues will be able to provide correction of the deformity and may prevent the development of secondary bone deformities.

Key words: complete subtalar release; clubfoot; talipes equinovarus; children
D oğuştan çarpık ayak (DÇA), muhtemelen en sık karşılaşılan doğumsal bir ortopedik bozukluktur (1/1000 canlı doğum). ${ }^{[1]}$ Diz altındaki hemen hemen bütün kas-iskelet sistemi elemanları (kas, tendon, bağ, kemik, damar) etkilenmiştir. Her ne kadar konservatif veya cerrahi tedavilerin erken dönem sonuçları iyi olarak bildirilmekteyse de, ayağın normale dönmesinin çok zor hatta bazen de mümkün olmadığı asla unutulmamalıdır. Bu derleme makalede, DÇA tedavisinde uygulanan yumuşak doku cerrahi girişimleri anlatılacaktır.

\section{DÇA'NIN PATOFIZYOLOJisi}

DÇA'ya neden olan anatomik bozukluklar, aslında yıllar önce (1803 yılında) Scarpa tarafından tanımlanmıştır. Scarpa'ya göre; navikula, küboid ve kalkaneus kemikleri, talus etrafında mediyal ve plantara doğru dönmektedir. Eşlik eden yumuşak doku kontraktürleri, bu varus ve ekin deformitesini sabit hale getirmektedir. ${ }^{[2]}$ Sonuç olarak, ayak bileği ve subtalar eklemde ekin, topukta inversiyon (varus), ayak ortası ve önünde adduksiyon-pronasyon deformiteleri gözlenir. Son yıllarda yapılan manyetik rezonans (MR) görüntüleme çalışmaları, Scarpa'nın gözlemlerinin doğru olduğunu kanıtlamaktadır. ${ }^{[3,4]}$ Scarpa, Adams ve Elmslie, DÇA patogonezinde talusun birincil derecede önemli olmadığını, daha çok ayak ortası yarı çıkıklarının önemli olduğunu vurgulamışlardır. ${ }^{[5]}$ Daha sonraları, DÇA patogenezinde talusun önemi anlaşılmış ve talus başının yuvasından (asetabulum pedis) çıkmasının önemi vurgulanmıştır. ${ }^{[6-9]}$ Yapılan çalışmalar sonucunda, talus boynunun kısaldığı, cisminin daraldığı, başının mediyal ve plantara yöneldiği, subtalar eklemin orta ve ön fasetlerinin gelişim defekti gösterdiği anlaşılmıştır. ${ }^{10-12]}$ Tibianın içe dönüklüğünün eşlik edip etmediği konusunda ise çelişkili çalışmalar mevcuttur. ${ }^{[13,14]}$ DÇA patofizyolojisinin ayrıntılı anlatımı bu makalenin amacı dışında olduğu için, bundan sonraki bölümde yumuşak dokulara yönelik cerrahi tedavi ayrıntılarıyla irdelenecektir.

- İletişim adresi: Doç. Dr. Önder Kalenderer, Tepecik Eğitim ve Araştırma Hastanesi, İzmir 

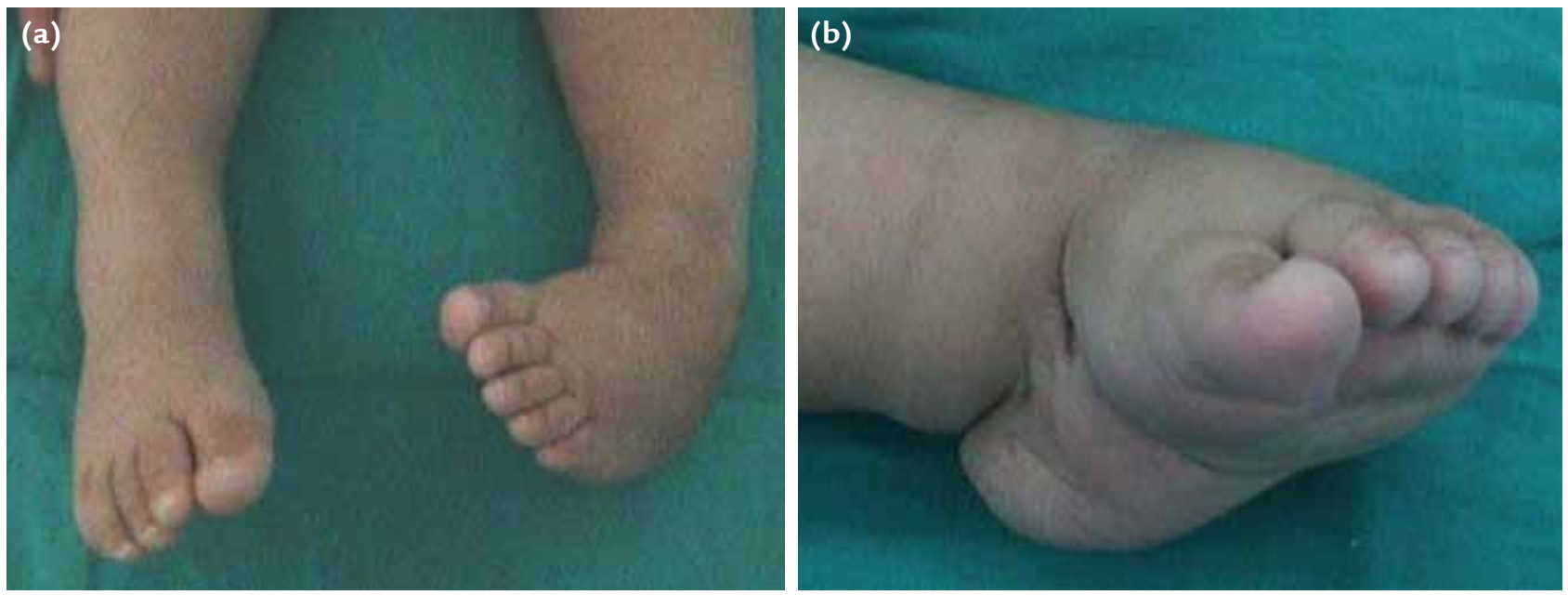

Şekil 1. a, b. Doğuştan çarpık ayak deformitesinin klasik görüntüleri.

\section{Yumuşak Dokularda Saptanan Bozukluklar}

Yapılan çalışmalarda; tibialis posterior, fleksör hallusis longus, fleksör dijitorum longus, gastroknemius ve soleus kaslarının kısaldığı, peroneus longus kasının ise normale göre uzun olduğu saptanmıştır. ${ }^{[15]}$ Tibialis posterior ve tibialis anterior tendonları, ayak inversiyonuna bağlı olarak öne doğru deplase olmuştur. Ayağın kısa fleksör kasları ve plantar fasya da gergindir. Navikulanın talus başına redüksiyonunu engelleyen yapılar; spring (kalkaneonaviküler) bağ, talonaviküler kapsülün üst ve iç kısmı, tibionaviküler bağ ve kapsül, Henry düğümü, kalkaneofibular bağ, üst peroneal retinakulum, arka tibiotalar kapsül, arka tibiokalkaneal bağ ve interosseöz bağdır. Ayağın klasik görünümü, Şekil 1'de görülmektedir.

\section{TEDAVi}

DÇA'lı hastaların tedavilerinde hedef, ağrısız, esnek ve yere düz basan bir ayak oluşturmaktır. DÇA'lı bir bebekle karşılaşılan ilk andan itibaren, yumuşak doku kontraktürlerinin ve kemiksel deformitelerin önüne geçilebilmesi adına, alçıla konservatif tedaviye başlanmalıdır. Konservatif tedavide, tarihsel olarak başlıca Kite, ${ }^{[16]}$ Ponseti, ${ }^{[17]}$ ve Fransız fonksiyonel tedavi metodları ${ }^{[18]}$ kullanılagelmiştir. Konservatif tedavi yöntemleri genel olarak başarı ile sonuçlanmalarına karşın, \%40'ın üzerinde deformitenin tekrar oluştuğu, uzun süre alçılama gerektiği ve geniş yumuşak doku ve kemik ameliyatlarının gerekli olabileceği bildirilmiştir. ${ }^{[19-21]}$

Cerrahi düzeltme, konservatif tedaviye yanıt vermeyen deformitelerde son şans olarak kullanılmalıdır. Her ne kadar cerrahi tedavilerle ciddi deformitelerin düzeltilebileceği öngörülse de, bu konuda literatür bilgileri net değildir. Sertliğin artması, skarların derinleşmesi, yumuşak dokuların gerginleşmesi ve immobilizasyona bağlı atrofiden dolayı, tekrarlayan cerrahi tedavilerden kaçınılmalıdır. IIlk cerrahi girişim sonrasında en iyi düzeltme elde edilmelidir. Tekrarlayan cerrahi tedavi gereksinimlerinin en sık nedeni önceki yetersiz düzeltmelerdir. Yetersiz düzeltmeler ve konservatif tedavi sonrası oluşan nüksler, bu konuda deneyimi olan cerrahlar tarafından değerlendirilmeli ve gerekli ameliyatlar yapılmalıdır. İdiyopatik DÇA'ı hastaların yaklaşık \%15'i tam posteromediyal gevşetmeye ihtiyaç duymaktadırlar.

\section{Cerrahi Zamanlama}

Bir hastada konservatif tedavinin başarısız olacağı öngörüldüğünde, talus başı düzleşmesi gibi muhtemel ikincil kemik bozukluklarının oluşmasının engellenebilmesi açısından, zaman kaybetmeden cerrahi tedavi planlanıp uygulanmalıdır. ${ }^{[22]}$ Dimeglio ve Pous, önceleri her ne kadar 1-6 haftalık bebeklerde cerrahi gevşetmeler yapmış olsalar da, artmış skar dokusu ve tekrarlayıcı fibrozis nedeni ile bu uygulamalarından vazgeçmişlerdir. ${ }^{[23]}$ Turco ise, hem dokulara hakimiyet hem de onarılan dokuların doğru pozisyonda yeterince tespit edilebilmeleri açısından, cerrahi tedavinin bir yaş ve sonrasında uygulanmasını önermiştir. ${ }^{[24]}$ Günümüzde, beş aylığa kadar olan hastalarda dahi cerrahi tedavi uygulanabileceği ileri sürülmesine rağmen, bu kadar erken cerrahi uygulanan hastaların, yürüyene kadar nüksü önlenmek için cihaz kullanmaları zorunludur. Tüm bu nedenlerden dolayı, cerrahi için en uygun zaman $9-10$ ay arasıdır. 


\section{Yumuşak Doku Gevşetme Ameliyatları}

DÇA'da tam anatomik düzeltmenin başarılabilmesi için tanımlanmış birden fazla cerrahi teknik mevcuttur. Bu tekniklerden ilki, 1971 yılında Turco tarafindan ortaya atılmıştır. Turco, hasta supin pozisyonda yatarken eğri posteromediyal insizyon kullanarak, subtalar bölgede lateral, posterior, mediyal gevşetmeler yaparak, tam subtalar düzeltmeyi hedefler ve gevşetmelerine kalkaneofibular bağı da ekler. Turco'nun tanımladığı yöntem, daha sonraları ihtiyaçlar doğrultusunda, onun adına modifiye edilmiştir. Carroll, ön ayak adduksiyon ve supinasyonunun (kavus) Turco'nun tanımladığı yöntem ile giderilemediğine dikkat çekerek, abduktor hallusis kası, plantar fasya ve kalkaneoküboid eklemin de gevşetilmesi gerektiğini vurgulamıştır. ${ }^{[25]}$ Talusun rotasyonunun deformitenin oluşumunda birincil sorumlu olduğuna inanan Goldner, buna derin mediyal deltoid bağların da gevşetilmesini ve sonra gerekli olursa onarılmasını içeren subtalar gevşetme ve sinus tarsiye uyan lateral insizyonla kalkaneoküboid kapsülotomi eklemiş ve aynı insizyondan lateral talonaviküler kapsülorafi uygulanmasını da önermiştir. ${ }^{[26]}$ Daha geniş kapsamlı girişimler, McKay ve Simons tarafindan Cincinnati insizyonu kullanılarak tüm talus çevresi, ayak arka ve orta eklemlerinin gevşetilmesi şeklinde uygulanmıştır. ${ }^{[27,28]}$ Tüm bu girişimlerde mutlaka Aşil tendonunun uzatılması önerilmektedir.

Kliniğimizde, DÇA'lı bebeklere en erken dönemde konservatif tedaviye başlanmaktadır. Konservatif tedavide, Ponseti tarafından tanımlanan yöntem uygulanmaktadır. Ortalama 6-8 alçılama sonrası, Aşil tendon uzatması, posterior tibiotalar ve subtalar eklem kapsülotomileri ve kalkaneofibular bağ gevşetilmesi yapılmaktadır. Hastaların erken dönem sonuçları genellikle başarılıdır. Tedaviye dirençli ve artrogripotik ayaklarda, nörolojik hastalığa ikincil deformitesi olan, nüks gelişen ve ihmal edilmiş hastalarda, kısmi hatta bazen tam subtalar gevşetmeye ihtiyaç duyulmaktadır.

Hastaya, genel anestezi ve/veya kaudal epidural anestezi sonrası, supin pozisyonda ameliyat uygulanır. Steril Esmarch bandajı ile alt ekstremite venöz kanı boşaltıldıktan sonra, kesi uygulanır. Cerrahi kesi, düzeltilmesi gerekli olan deformiteye göre; posteromediyal, posteromediyal-lateral veya Cincinnati insizyonu şeklinde yapılabilir. Önemli olan, kesi altındaki tüm deformitelerin görülebilmesi ve düzeltilebilmesidir. Cerrahların çoğu, kozmetik olarak avantajlı olduğu, geniş görüş sağladığı ve güvenli olduğu için, Cincinnati insizyonunu tercih etmektedir. Bu insizyonda topuk dolaşımının korunması için, kesi posterior krizin en az $1 \mathrm{~cm}$ üzerinden yapılmalıdır. ${ }^{[29-30]}$ ilk olarak Aşil, Z plasti şeklinde uzatilır. Posterior tibiotalar ve subtalar kapsüller, kalkaneofibular bağ kesilir. Kavus, adduktus ve varus

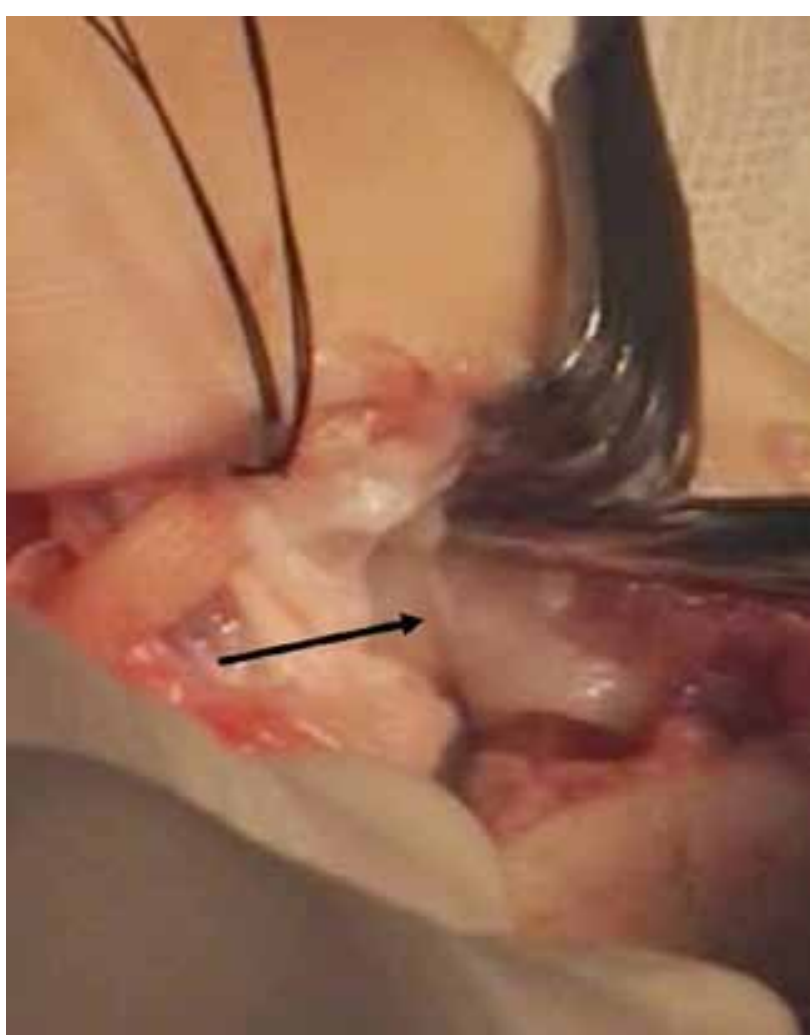

Şekil 2. Gevşetilmiş talonaviküler eklem (siyah ok).

varlığında, plantar fasya kesilir ve abduktor hallusis kası kalkaneusa yapışma yerinden gevşetilir. Eğer talonaviküler eklem redükte değil ise, tibialis posterior tendonu $\mathrm{Z}$ şeklinde uzatılır. Bu uzatmaya rağmen halen redüksiyon sağlanamadıysa, talonaviküler kapsül mediyalden başlanarak plantar ve dorsale doğru gevşetilir (Şekil 2). Navikulanın alt kısmında bulunan Y (spring) bağının gevşetilmesi oldukça önemlidir. Talonaviküler eklemin çok fazla gevşetilmesi instabiliteye neden olabileceğinden, dikkatli davranılmalıdır. Henry düğümü, fleksör tendonları bulmak açısından önemlidir. Düğüm bulunur ve gevşetilir. Fleksör hallusis longus ve fleksör dijitorum longus tendonları, mediyal damar-sinir paketi askıya alındıktan sonra uzatılmalıdır (Şekil 3. a-c). Yapışıklığın önlenebilmesi açısından, bu uzatma işlemleri ayak ortasında yapılmamalıdır. İnterosseöz bağ, çok yönlü rotasyonun menteşe noktası olduğundan dolayı korunur; fakat, CSTR (Complete Subtalar Release)'nin orijinalinde kesilmesi önerilmektedir. Deltoid bağın derin kısmı mutlaka korunmalıdır. Ardından uzatılan dört tendon (FHL, FDC, Aşil ve tibialis posterior) uygun gerginlikte onarılır. Posteromediyal gevşetmeler tamamlandıktan sonra ayak önü nötralden abduksiyona getirilerek (eğer abduksiyon sağlanamıyorsa) lateral gevşetme gerekip 

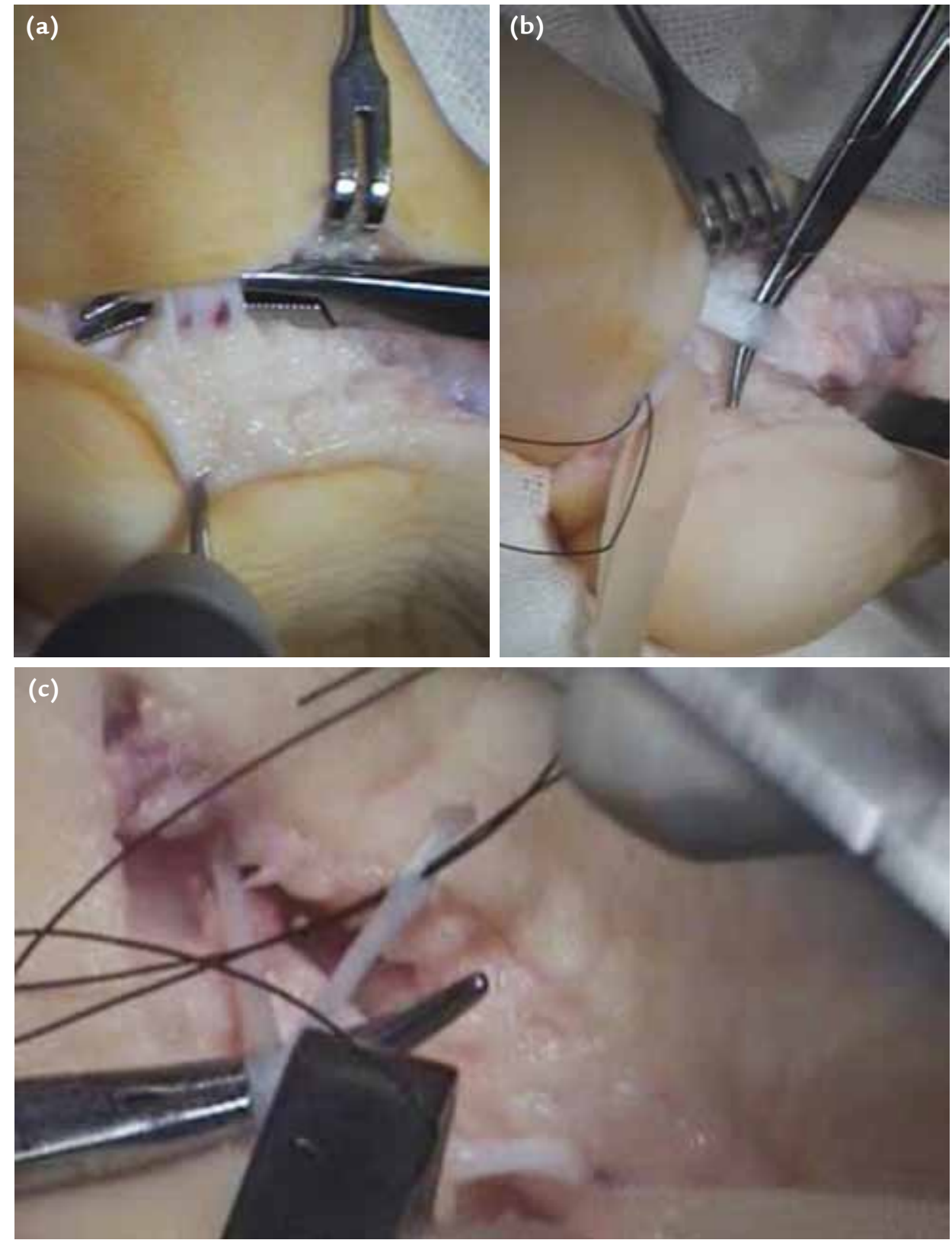

Şekil 3. a-c. Askıya alınmış mediyal damar sinir paketi (a). Tibialis posterior tendonu (b). Tibialis posterior, fleksör dijitorum longus ve fleksör hallusis longus tendonlarının Z şeklinde uzatılmak için hazırlanması (c).

gerekmediğine karar verilir. Ayak önü nötralden öteye abduksiyona getirilemiyorsa, ayrıca lateral subtalar kapsül ve kalkaneoküboid eklem kapsülü de gevşetilmelidir. ${ }^{[31]}$ Gevşetmeler sonrası talustan naviküler ve kalkeneustan talusa giden birer adet Kirscher teli gönderilir. Kanama kontrolünü takiben, katlar kapatılır. Kapatma esnasında topuğun arka bölgesinde ciltte gerginlik varsa, yara iyileşene kadar ayak ekin pozisyonunda alçılanır ve tedrici olarak ekini azaltacak alçılamalar yapılır.
Alçı ve K-telleri 6-8 haftada çıkarılır. Ardından germe egzersizleri uygulanır ve AFO (Ankle-Foot-Orthosis) cihazı verilir. Cihaz, 3-6 ay arası uygulanır. Ancak, iyi bir cerrahi tedavi sonrası nüksü engelleyen en önemli şey, cihazdan çok egzersizdir. Kimi cerrahlar 6-7 yaşlara kadar çeşitli ayakkabılar önerse de, günlük pratikte bunlar çok kullanılmamaktadır. CSTR ile tedavi edilmiş bir hastanın ameliyat öncesi, erken ameliyat sonrası ve kontrol röntgenleri Şekil 4'te gösterilmiştir. 

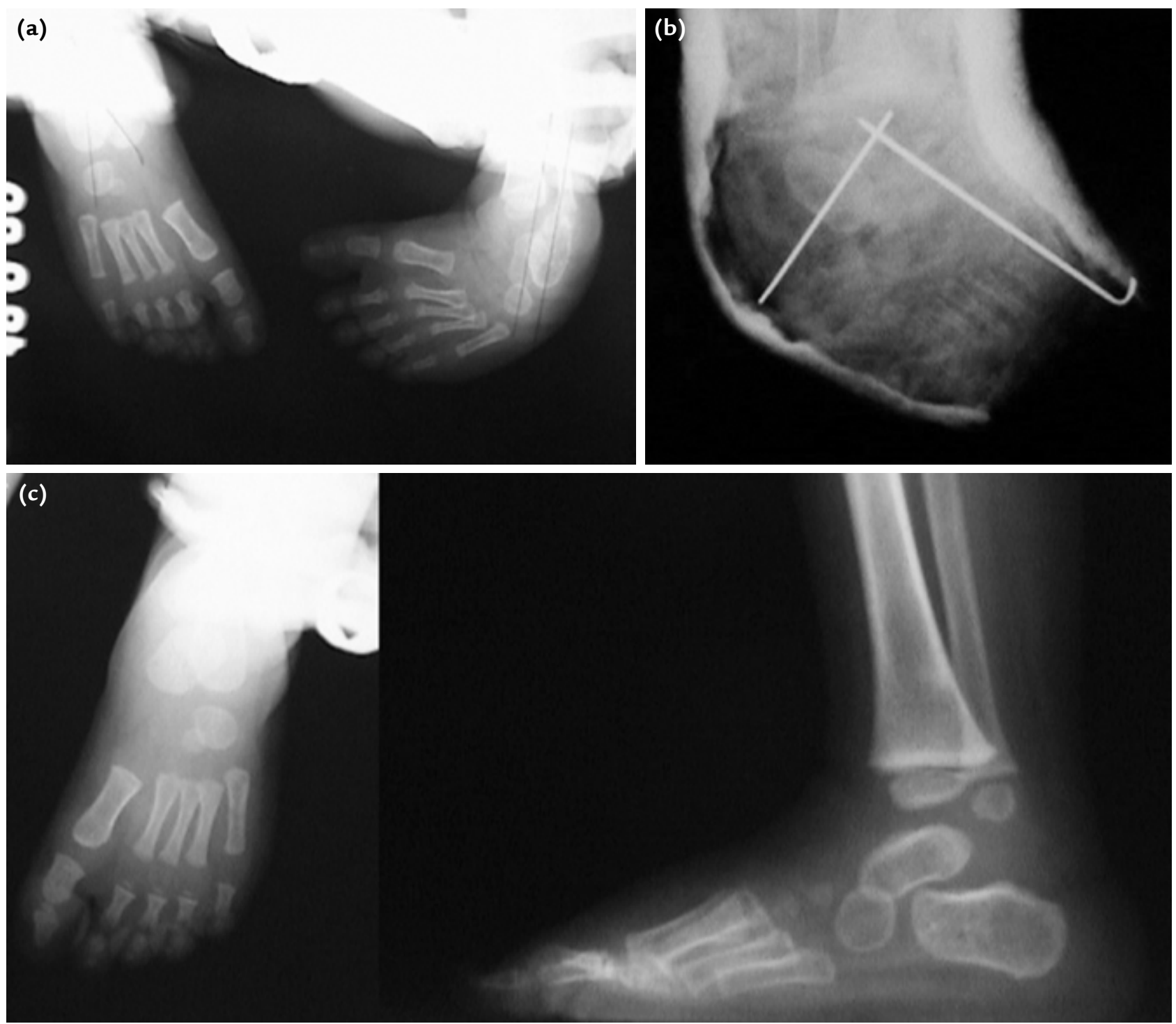

Şekil 4 a-c. Doğuştan çarpık ayaklı bir olgunun ameliyat öncesi (a), erken ameliyat sonrası (b) ve kontrol (c) röntgenleri.

\section{KAYNAKLAR}

1. Wynne-Davies R. Genetic and environmental factors in the etiology of talipesequinovarus. Clin Orthop Relat Res 1972;84:9-13.

2. Ponseti IV. Congenital clubfoot: Fundamentals of Treatment, Oxford: Oxford Medical Publications; 1996.

3. Kamegaya M, Shinohara Y, Kokuji Y, Moriya H. Evaluation of pathologic abnormalities of clubfoot by magnetic resonance imaging. Clin Orthop Relat Res 2000;(379):218-23.

4. Saito S, Hatori M, Kokubun S, Abe Y, Kita A. Evaluation of calcaneal malposition by magnetic resonance imaging in the infantile clubfoot. J Pediatr Orthop B 2004;13(2):99-102.

5. Elmslie R. The principles of treatment of congenital talipes equino-varus. J Bone Joint Surg 1920;2:669.
6. EvansD. Relapsed clubfoot.J Bone JointSurg Br1961;43-B:722-33.

7. Epeldegui T, Delgado E. Acetabulum pedis. Part II: Talocalcaneonavicular joint socket in clubfoot. J Pediatr Orthop B 1995;4(1):11-6.

8. Cahuzac JP, Navascues J, Baunin C, Salles De Gauzy J, Estivalezes E, Swider P. Assessment of the position of the navicular by three-dimensional magnetic resonance imaging in infant foot deformities. J Pediatr Orthop B 2002;11(2):134-8.

9. Wang C, Petursdottir S, Leifsdottir I, Rehnberg L, Ahlström $\mathrm{H}$. MRI multiplanar reconstruction in the assessment of congenital talipes equinovarus. Pediatr Radiol 1999;29(4):262-7.

10. Shapiro F, Glimcher MJ. Gross and histological abnormalities of the talus in congenital club foot. J Bone Joint Surg Am 1979;61(4):522-30. 
11. Tachdjian M. The foot and leg. In: Tachdjian M, editor. Pediatric orthopaedics. Philadelphia: Saunders; 1990. p. 2517.

12. Smith RB. Dysplasia and the effects of soft tissue release in congenital talipes equinovarus. Clin Orthop Relat Res 1983;(174):303-9.

13. Loren GJ, Karpinski NC, Mubarak SJ. Clinical implications of clubfoot histopathology. J Pediatr Orthop 1998;18(6):765-9.

14. Cuevas de Alba C, Guille JT, Bowen JR, Harcke HT. Computed tomography for femoral and tibial torsion in children with clubfoot. Clin Orthop Relat Res 1998;(353):203-9.

15. Isaacsh $H$, Handelsman JE, Badenhorst M, Pickering A. The muscles in club foot -a histological histochemical and electron microscopic study. J Bone Joint Surg Br 1977;59-B(4):465-72.

16. Kite JH. Non operative treatment of congenital clubfoot. Clin Orthop Relat Res 1972;84:29-38.

17. Ponseti IV. Clubfoot management. J Pediatr Orthop 2000;20(6):699-700.

18. Richards BS, Johnston CE, Wilson H. Nonoperative clubfoot treatment using the French physical therapy method. J Pediatr Orthop 2005;25(1):98-102.

19. Faulks S, Richards BS. Clubfoot treatment: Ponseti and French functional methods are equally effective. Clin Orthop Relat Res 2009:467(5):1278-82. CrossRef

20. Sud A, Tiwari A, Sharma D, Kapoor S. Ponseti's vs. Kite's method in the treatment of clubfoot -a prospective randomised study. Int Orthop 2008;32(3):409-13.

21. Moon DK, Gurnett CA, Aferol H, Siegel MJ, Commean PK, Dobbs MB. Soft-Tissue Abnormalities Associated with Treatment-Resistant and Treatment-Responsive Clubfoot : Findings of MRI Analysis. J Bone Joint Surg Am 2014;96(15):1249-56.
22. Macnicol M. Congenital talipes equinovarus (clubfoot). In: Helal B, editor: Surgery of disorders of the foot and ankle. London: Martin Dunitz; 1996. p.154.

23. Pous JG, Dimeglio A. Neonatal surgery in clubfoot. Orthop Clin North Am 1978;9(1):233-40.

24. Turco VJ. Surgical correction of the resistant club foot. One-stage posteromedial release with internal fixation: a preliminary report. J Bone Joint Surg Am 1971;53(3):477-97.

25. Carroll NC, McMurtry R, Leete SF. The pathoanatomy of congenital clubfoot. Orthop Clin North Am 1978;9(1):225-32.

26. Goldner JL. Congenital talipes equinovarus -fifteen years of surgical treatment. Curr Pract Orthop Surg 1969;4:61-123.

27. McKay DW. Dorsal bunions in children. J Bone Joint Surg Am 1983;65(7):975-80.

28. Simons GW. Complete subtalar release in club feet. Part II Comparison with less extensive procedures. J Bone Joint Surg Am 1985;67(7):1056-65.

29. Crawford AH, Marxen JL, Osterfeld DL. The Cincinnati incision: a comprehensive approach for surgical procedures of the foot aod ankle in childhood. J Bone Joint Surg Am 1982;64(9):1355-8.

30. Kalenderer O, Reisoglu A, Turgut A, Agus H. Evaluation of clinical and radiographic outcomes of complete subtalar release in clubfoot treatment. J Am Podiatr Med Assoc 2008;98(6):451-6.

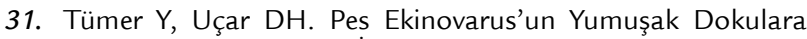
Yapılan Cerrahisi. TOTBID Dergisi 2002;1(2):71-6. 